\title{
Intensive chemotherapy as salvage treatment for solid tumors: focus on germ cell cancer
}

\author{
F. Selle ${ }^{1,2}$, J. Gligorov ${ }^{1,2}$, S. Richard ${ }^{1}$, A. Khalil ${ }^{1}$, I. Alexandre ${ }^{3}$, D. Avenin ${ }^{1}$, S. Provent ${ }^{1}$, \\ D.G. Soares ${ }^{1}$ and J.P. Lotz ${ }^{1,2}$ \\ ${ }^{1}$ Medical Oncology and Cellular Therapy Department, Hospital Tenon, Public Assistance Hospitals of Paris, \\ Alliance for Cancer Research (APREC), Paris, France \\ ${ }^{2}$ Pierre \& Marie Curie University (UPMC Paris VI), Paris, France \\ ${ }^{3}$ Medical Oncology Department, Hospital Centre of Bligny, Briis-sous-Forges, France
}

\begin{abstract}
Germ cell tumors present contrasting biological and molecular features compared to many solid tumors, which may partially explain their unusual sensitivity to chemotherapy. Reduced DNA repair capacity and enhanced induction of apoptosis appear to be key factors in the sensitivity of germ cell tumors to cisplatin. Despite substantial cure rates, some patients relapse and subsequently die of their disease. Intensive doses of chemotherapy are used to counter mechanisms of drug resistance. So far, high-dose chemotherapy with hematopoietic stem cell support for solid tumors is used only in the setting of testicular germ cell tumors. In that indication, high-dose chemotherapy is given as the first or late salvage treatment for patients with either relapsed or progressive tumors after initial conventional salvage chemotherapy. High-dose chemotherapy is usually given as two or three sequential cycles using carboplatin and etoposide with or without ifosfamide. The administration of intensive therapy carries significant side effects and can only be efficiently and safely conducted in specialized referral centers to assure optimum patient care outcomes. In breast and ovarian cancer, most studies have demonstrated improvement in progressionfree survival (PFS), but overall survival remained unchanged. Therefore, most of these approaches have been dropped. In germ cell tumors, clinical trials are currently investigating novel therapeutic combinations and active treatments. In particular, the integration of targeted therapies constitutes an important area of research for patients with a poor prognosis.
\end{abstract}

Key words: High-dose chemotherapy; Germ cell tumors; Stem cell transplantation; Solid tumors; Breast cancer; Ovarian cancer

\section{Introduction}

The concept of high-dose chemotherapy (HDCT) arose from in vitro observations that exposure of tumor cells to increasing doses of certain cytotoxics resulted in increased cell death in a dose-response manner. The dose response seen in vitro translated clinically into the creation of HDCT protocols. Additionally, the understanding of chemotherapeutic resistance, the principal obstacle in cancer treatment, reinforced the study of high-dose treatment approaches.

In the 1980s, Frei et al. (1) demonstrated that resistance acquired by tumor cells during treatment with alkylating agents (nitrosourea and carmustine/BCNU) was maintained by intermittent treatment with low concentrations of chemotherapy agents. However, resistance could be overcome by dose intensification, i.e., by multiples of 5 to 10 .

Combination chemotherapy was initially used to overcome resistance, and this was supported by in vitro observations. In the 1980s, it was demonstrated that not all alkylating agents are subject to cross-resistance and could work synergistically when administered with platinum compounds (1). Study of the molecular basis of agents with different mechanisms of action greatly contributed to the development of multiple-agent chemotherapy. Protocols including combinations of multiple agents in intensive therapy were developed with the intention of delaying or preventing the emergence of resistant clones (2).

In the 1980s, progress in hematology and oncology allowing the possibility of expanding ex-vivo reserves of hematopoietic stem cells gave hope to intensive chemotherapy treatments. There was a marked increase in experimental protocols testing the feasibility and efficacy of intensive chemotherapy with autologous hematopoietic stem cell transplantation.

Before proceeding with autologous transplantation, it is critical to mobilize and collect an adequate number of

Correspondence: Frédéric Selle: <frederic.selle@tnn.aphp.fr>.

Received July 2, 2014. Accepted September 15, 2014. First published online November 4, 2014. 
hematopoietic stem cells. The mobilization step is needed to promote changes in the bone marrow microenvironment, allowing the release of hematopoietic stem cells into the vascular system. These changes include disruption of the adhesion between hematopoietic stem cells and stromal cells and alteration of the chemotactic gradients. Administration of agents that target chemokine receptors and adhesion factors directly (e.g., CXCR4 and VLA4 antagonists) will mobilize hematopoietic stem cells within hours of administration. In contrast, treatment with granulocyte-colony stimulating factor (G-CSF) or chemotherapy (cyclophosphamide) requires several days before the effect is achieved (3).

Mobilization practices vary significantly among institutions. Effective mobilization regimens include growth factor alone, chemotherapy and growth factor combined, and more recently, the incorporation of plerixafor associated with either approach (4). In the setting of solid tumors, mobilization is generally achieved by the administration of chemotherapy and G-CSF. Indeed, it has been shown that chemotherapy also induces hematopoietic stem cell proliferation prior to mobilization (5) and helps to improve CD34 + cell yield (3).

Chemotherapy-induced mobilization is generally achieved during the marrow recovery phase following disease-specific chemotherapy protocols. The use of autologous hematopoietic cell support derived from peripheral blood progenitor cells following HDCT is summarized in Figure 1. The use of mobilized peripheral blood stem cells allowed the inclusion of intensive chemotherapy in the therapeutic arsenal of solid tumor treatments, primarily germ cell tumors (GCTs), breast, and ovarian cancers. Currently, HDCT is a therapeutic option only in the treatment of GCTs.

\section{Biological aspects of GCTs and response to treatment}

GCTs, and in particular testicular germ cell tumors, are relatively rare and mainly affect young men, becoming most prevalent around the age of 30 years (5). Approximately $95 \%$ of primary testicular tumors arise from embryonic germ cells, either primordial germ cells (PGCs) or gonocytes, and, as such, are more appropriately referred to as testicular GCTs. Other germ cell tumors can arise outside the testis, typically in midline locations, with the mediastinum, retroperitoneum, and brain constituting the most common extragonadal primary tumor sites. This anatomical distribution is possibly related to the migration route of PGCs during embryogenesis (6). Histopathologically, testicular GCTs can be classified into two major groups, seminomas and nonseminomas, each comprising $50 \%$ of cases, with the latter category also including tumors with mixed components. The seminomas are composed of cells that are morphologically similar to those of PGCs and carcinoma in situ.
Most nonseminomas are of mixed histology, including components such as embryonic cells, yolk sac tumor, choriocarcinoma and teratoma. These two subtypes share several risk factors but have distinct clinical characteristics and treatment modalities. Seminomas are radio- and chemosensitive tumors (7). Nonseminomas are usually treated with surgery and chemotherapy, and have different cure rates depending on the disease stage (8).

A particularity of GCTs is that the majority of patients can expect to be cured, even in the presence of metastatic disease (9). As most GCTs can be cured by chemotherapy, and in some cases by surgery alone, lessons learned from the biology of this disease may help to treat other solid tumors more effectively. In that context, the intrinsic properties of this malignancy, as well as the initiating events of the disease, have been investigated for more than 30 years. The genetic events that lead to the development of intratubular germ cell neoplasia, unclassified (IGCNU or carcinoma in situ) and subsequent to invasive GCTs, are not completely understood. The only consistent structural chromosomal abnormalities in invasive testicular GCTs are gains of the short arm of chromosome 12 , mostly due to isochromosome (i(12p)) formation $(10,11)$. In addition, even if some testicular GCTs lack $i 12 p$ they harbor amplifications of $12 p$ genetic material. The gain of $12 p$ seems to be associated with the invasive phenotype of testicular GCTs (12). Importantly, several genes map to this region and may be important for the pathogenesis of GCTs (13), including K-RAS (14) and cyclin D2 (CCND2) $(6,15)$. This critical role of $12 p$-derived genes in invasive testicular GCTs is known, but its relationship to the chemosensitivity of these tumors remains to be proven.

Following the simple addition of cisplatin to bleomycin and vinblastine in the 1970s (16), 5-year survival rates of GCT patients increased drastically, from $25 \%$ to nearly $95 \%$ in 2008 (17). These unique response rates have been linked to an intrinsic hypersensitivity to DNAdamaging agents, as observed in several embryonic carcinoma cell lines derived from testicular GCTs $(18,19)$.

Interestingly, GCT tumors show contrasting biological and molecular features to other solid malignancies. For example, p53 mutations are infrequent in testicular GCTs $(20,21)$. This suggests that the p53 pathway could play an important role in the striking apoptotic response observed in testicular GCTs following DNA damage, and is consistent with the demonstration that cisplatin hypersensitivity relies heavily on a functional p53 protein (22-24). In addition, the absence of the retinoblastoma protein, which normally regulates the G1/S transition, in germ cells and testicular GCTs, may favor the elimination of genetically damaged cells by facilitating their entry into $S$ phase and then leading to their death by apoptosis (25).

Finally, the expression of the ERCC1-XPF endonuclease is low in GCTs compared to other tumor types (26). 


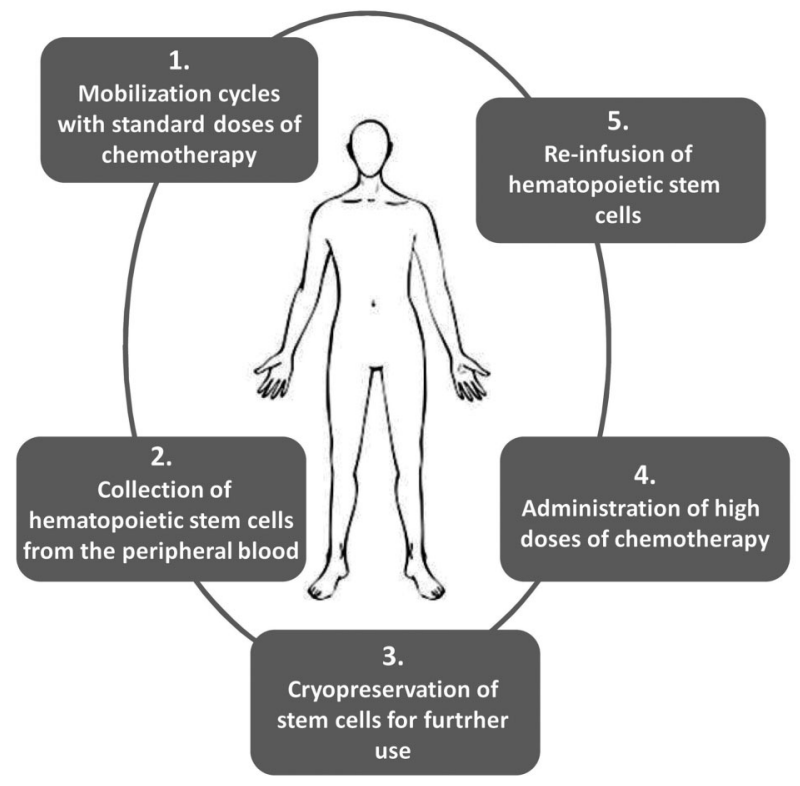

Figure 1. Autologous peripheral blood stem-cell transplant process. High-dose chemotherapy (HDCT) carries significant bone marrow toxicity, which leads to the necessity of autologous hematopoietic stem cell harvest and transplantation during treatment intensification. The use of peripheral blood as a source of stem cells for hematopoietic stem cell transplant rather than bone marrow greatly contributed to the application of HDCT in the treatment of solid tumors. This procedure simplified the harvest of stem cells and considerably decreased morbidity and mortality associated with HDCT, decreasing length of hospitalization and reducing treatment costs. Furthermore, the use of hematopoietic growth factors allowed increased cytotoxic dosing. The granulocyte colony-stimulating factor (G-CSF) is administrated to accelerate leukocyte recovery after HDCT.

This is important because the most frequent DNA lesions induced by cisplatin are intrastrand crosslinks that occur between two guanines or a guanine and an adenine. These account for about $90 \%$ of all platinum-induced DNA lesions. Cisplatin also induces interstrand DNA crosslinks (ICLs), a minor type of DNA lesion that accounts for less than $5 \%$ of all cisplatin-induced DNA lesions (27). Interestingly, while intrastrand crosslinks are repaired by nucleotide excision repair (NER), ICLs are removed by ICL repair (28). Intriguingly, both DNA repair pathways involve the ERCC1-XPF endonuclease, suggesting that the low expression of ERCC1-XPF in testicular GCTs might contribute to their high sensitivity to cisplatin. Surprisingly, even with reduced levels of ERCC1-XPF, testicular tumor cells are generally considered as NER proficient and are able to repair UV-induced photoproducts, which are exclusively removed by NER (29). Thus, despite their low frequency, ICLs may be the critical type of cytotoxic DNA lesion induced in testicular GCTs by cisplatin. They would not be repaired because of low ERCC1-XPF expression, consequently leading to tumor cell death (30).

Conversely, acquired cisplatin resistance is often correlated with increased ERCC1 expression in cellular models (31) and clinical studies have shown that high levels of ERCC1 expression are associated with resistance to platinum-based chemotherapy in various human cancers. ERCC1 may thus be a reliable predictive marker of cisplatin resistance (32).

In addition to NER, Cavallo et al. (33) used both a green fluorescent protein (GFP)-based assay of DNA double-strand break repair by homologous recombination (HR) and an assay of cisplatin-induced formation of Rad51 foci in embryonic carcinoma cell lines to show that reduced HR activity correlated with testicular GCT sensitivity to cisplatin.

The reduced ability of testicular GCTs to repair cisplatin-induced DNA damage, and their enhanced response to p53-mediated apoptosis, are certainly characteristics inherited from the cells of origin (PGCs or gonocytes) because cisplatin sensitivity is inversely correlated with the degree of differentiation. Indeed, the loss of embryonic features observed in mature teratomas correlates with increased cisplatin resistance (34). Similarly when the embryonic carcinoma cell lines NTERA-2D1 (NT2/D1) and Tera-2 were induced towards terminal differentiation by treatment with retinoic acid, they lost their hypersensitivity to cisplatin treatment $(34,35)$.

Regarding new strategies targeting GCTs, particularly tumors resistant to cisplatin-based chemotherapy, the role of HR repair demonstrated in embryonic cells suggests that poly (ADP-ribose) polymerase (PARP) inhibitors might be a promising treatment for these tumors. It has been shown that one such inhibitor, AZD2281, potentiates the cytotoxic activity of cisplatin by promoting p53dependent apoptosis (36).

Another approach would be to introduce mouse double minute 2 (MDM2) inhibitors. Indeed, it has been demonstrated that p53 resides in a complex with MDM2 in cisplatin-resistant human testicular cancer cells compared to cisplatin-sensitive testicular cancer cells. The inhibition of the MDM2-p53 interaction by either Nutlin-3 or MDM2 RNA interference leads to hyperactivation of the p53 pathway and a strong induction of apoptosis in the resistant cells (37).

\section{HDCT in the treatment of GCTs}

For poor-prognosis patients (38), the current standard of care in first-line therapy is the three-drug combination of bleomycin, etoposide, and cisplatin (BEP) (39). Despite the considerable cure rate of the BEP regimen, 10 to $20 \%$ of patients relapse and subsequently die of their disease, particularly those with an intermediate or poor prognosis (40). Poor-prognosis patients who relapse following BEP are candidates for initial salvage therapy with VeIP 
(vinblastine-ifosfamide-cisplatin), VIP (the same as VelP with etoposide in place of vinblastine), or a combination of ifosfamide and platinum salts with paclitaxel (TIP) with or without subsequent surgery (41-43).

Another option is intensification therapy, which can be given as a) first-line treatment for intermediate or poor-risk patients, or b) second-line (or first-salvage) treatment of recurrent/refractory, poor-prognosis patients with GCTs.

\section{First-line treatment for intermediate or poor-risk patients}

HDCT plus autologous hematopoietic stem cell support has been evaluated as part of first-line therapy by several studies (44-52). However, key trials in such a setting have demonstrated that this approach is not recommended. The initial study hypothesis was not verified in a two-arm phase III trial including patients with previously untreated metastatic nonseminomatous germ cell tumors (NSGCT). The study compared the effectiveness of four cycles of PVeBV (vinblastine, etoposide, cisplatin, and bleomycin) with a slightly modified regimen followed by HDCT including etoposide, cisplatin, and cyclophosphamide (PVBV+PEC). A complete response (CR) was achieved by $56 \%$ of patients in the first and $42 \%$ in the second study arm $(P=0.099)$, and no significant difference in the overall survival (OS) curves $(P=0.167)$ was observed (50). Another phase III trial evaluating conventional-dose chemotherapy with or without HDCT (BEP or BEP + HDCT) for previously untreated GCT patients with metastases and poor-prognostic clinical features found that routine inclusion of HDCT in the first-line treatment did not improve outcomes (51). More recently, Daugaard et al. (52) showed that one cycle of standard-dose VIP plus three cycles of high-dose VIP were not better than four cycles of BEP. Although this study reported a 2-year failure-free survival (FFS) of $44.8 \%(95 \% \mathrm{Cl}: 32.5-56.4)$ for the standard-dose arm compared to $58.2 \%(95 \% \mathrm{Cl}: 48-71.9)$ for the high-dose arm, the difference was not statistically significant $(P=0.060)$.

\section{Second-line (or first-salvage) treatment of recurrent/refractory disease}

Since the majority of patients who require salvage treatment will ultimately die of their disease, trials evaluating the early use of HDCT as first salvage therapy were developed as a strategy to overcome resistance to conventional chemotherapy.

In a retrospective multicenter analysis, Lorch et al. (53) compared HDCT with conventional doses given as first-salvage therapy in different subgroups of patients determined by risk categories (54). They found an overall $56 \%$ decrease in the risk of progression after first-salvage treatment in favor of HDCT. These differences translated into an improved OS for all of the prognostic categories of patients except the low-risk group. Several factors are critical for improving the efficacy and reducing the toxicity of HDCT as salvage therapy for GCTs. Important prognostic variables include the number of cycles, administration time, and the interval between cycles. The feasibility and efficacy of several cycles of HDCT have been explored and established (55).

A trial of the TI-CE protocol (two cycles of paclitaxel + ifosfamide for stem cell mobilization followed by three cycles of high-dose carboplatin and etoposide) reported a progression-free survival (PFS) of $48 \%$ at 5 years and a global survival of $52 \%$ (median survival of 61 months) (56). The TI-CE regimen, developed at Memorial SloanKettering Cancer Center, is currently the salvage treatment of choice worldwide. The European Consensus Conference on Diagnosis and Treatment of Germ-cell cancer (57) recommends a regimen including carboplatin and etoposide without additional agents such as ifosfamide, cyclophosphamide, or thiotepa. Similarly, the Einhorn regimen (58), developed at Indiana University, also an HDCT approach accepted worldwide, includes two cycles of carboplatin and etoposide followed by infusion of peripheral blood stem cells.

Although the Einhorn and TI-CE regimens are both based on the administration of high-doses of carboplatin and etoposide, there are important differences between them. Indeed, the TI-CE includes the administration of three rather than two high-dose cycles, dosing of carboplatin by target area under the concentration-time curve $(A \cup C)$ rather than body surface area, and the absence of adjuvant oral etoposide (prescribed for 3 months following HDCT at Indiana University). Although a number of HDCT regimens have been evaluated in the treatment of GCT patients failing cisplatin-based chemotherapy, no standard treatment is currently universally adopted.

To date, the only phase III trial of first-line salvage comparing high-dose versus standard-dose chemotherapy included 280 patients from 43 institutions in 11 countries and showed no benefit in either PFS or OS (59). However, this trial did not evaluate tandem cycles of HDCT, but compared four cycles of conventional-dose chemotherapy (cisplatin, ifosfamide, and etoposide or vinblastine) to three such cycles followed by one single high-dose cycle (carboplatin, etoposide, and cyclophosphamide).

Determining whether or not HDCT is superior to standard doses of chemotherapy as first-line salvage therapy for patients with relapsed disease is still a controversial issue. The TIGER study, a prospective randomized phase III trial comparing conventional doses (TIP) with sequential HDCT (TI-CE), was designed to address this concern in a prospective manner (60). Hopefully, this international collaboration conducted in many centers across North America (United States and Canada), Europe (UK, Germany, France, Italy, Spain, and Denmark) and Australia will soon provide a definitive 
answer to this important question.

\section{Subsequent therapy after failure of second- or third- line treatment for poor-prognosis patients}

The use of HDCT in this setting includes patients with the poorest prognoses (e.g., those with refractory disease, failing second or subsequent lines of chemotherapy, or with a mediastinal primary tumor at diagnosis). HDCT has been offered as salvage therapy since the 1980s for patients who experience progression after two or three lines of treatment (61), but its success was initially limited by increased mortality associated with treatment, mostly related to severe myelosuppression. The collection of hematopoietic stem cells led to important improvements in the safety and efficacy of treatment by reducing toxicity.

Following encouraging results of pilot studies evaluating HDCT in the salvage setting, a trial published in 1989 (61) enrolled 33 patients who had either demonstrated progression on salvage therapy with ifosfamide and cisplatin, or had primary cisplatin-refractory disease. Patients received one or two cycles of HDCT (1200 mg/ $\mathrm{m}^{2}$ etoposide per cycle of HDCT in combination with escalating doses of carboplatin) followed by autologous stem cell rescue. The authors reported 35\% CR and three patients who remained in CR for more than 1 year. This was the first trial to suggest that HDCT could be curative in the salvage setting. After that, other drugs, such as cyclophosphamide or ifosfamide, were added to high-dose carboplatin/etoposide in an effort to improve efficacy (62).

Using the same approach as the TI-CE regimen, including several cycles of HDCT, an alternative salvage therapy for patients with poor-prognosis GCTs has been evaluated by the TAXIF studies $(63,64)$. In the TAXIF I regimen, a mobilization and therapeutic induction step with a combination of epirubicin and paclitaxel (Epi-Tax) was used in order to more easily allow the harvesting of hematopoietic stem cells, reduce tumor bulk, and prevent progression prior to high-dose treatment. After induction, patients received three courses of HDCT supported by peripheral blood stem cell transplantation. The first HDCT regimen consisted of an association of $400 \mathrm{mg} / \mathrm{m}^{2}$ thiotepa and $3 \mathrm{~g} / \mathrm{m}^{2}$ cyclophosphamide; the second and third HDCT courses were a combination of ifosfamide, carboplatin, and etoposide (ICE). The results showed that prognostic factors can predict outcomes after HDCT. Patients with highly refractory disease, particularly those with resistant/refractory primary mediastinal GCTs, did not benefit from HDCT. In this context, the TAXIF II program was developed based on the selection of nonrefractory patients who could benefit from the intensive chemotherapy. In that protocol, patients were sensitized with the Epi-Tax regimen before receiving high doses of chemotherapy. The 2-year PFS and the 2-year OS were 50 and $66 \%$, respectively. In terms of efficacy, the final overall response rate (ORR) was $48.8 \%$ and the median PFS and OS were 22 and 32 months, respectively. Overall, salvage treatment with TAXIF II was a feasible treatment that was tolerated by patients with sensitive relapsed disease. It is important to note that a retrospective analysis of patients treated by intensive doses of chemotherapy suggested a potential gain in survival even when this regimen is used as third line or later therapy (53). Supplementary Table S1 describes the most relevant studies on HDCT in the salvage setting for the treatment of GCT patients.

\section{Prognostic factors to guide GCTs treatment}

Prognostic factors for patients with metastatic GCTs at initial diagnosis were determined by the International Germ-Cell Cancer Cooperative Group (IGCCG) and are currently used worldwide for the selection of first-line treatments (38). However, for patients who undergo salvage therapy, the factors associated with long-term survival are less well established. In 1996, Beyer et al. (65) identified prognostic variables for treatment response after HDCT. Progressive disease before HDCT, mediastinal nonseminomatous primary tumor, refractory or absolutely refractory disease to conventional-dose cisplatin, and human chorionic gonadotropin (hCG) levels greater than $1000 \mathrm{IU} / \mathrm{L}$ before HDCT were identified as independent adverse prognostic variables for failure-free survival after HDCT. Thus, a prognostic score based on these variables was developed. Primary mediastinal tumors and an hCG level greater than 1000 IU/L were each assigned 2 points, whereas all other variables were assigned 1 point. For patients with a score of 3 or higher (the poor prognosis risk category), the rate of disease-free survival at 2 years was only $5 \%$, compared to $51 \%$ for patients with a Beyer score of 0 . This model, however, is not universally accepted.

More recently, the International Prognostic Factors Study Group conducted a large retrospective analysis to support clinical treatment decisions after failure of first salvage treatment. They collected information from 38 centers worldwide from 1984 patients who progressed after at least three cisplatin-based cycles and were treated with cisplatin-based conventional-dose or carboplatinbased high-dose salvage chemotherapy (54). Analysis of PFS rates at 2 years was the primary endpoint, and the prognostic score was defined by several parameters, including primary site, prior response, progression-free interval, alpha-fetoprotein levels, hCG levels, and liver/ bone/brain metastases. This new prognostic score estimated survival rates in five prognostic categories. For each category, the corresponding 2-year PFS rates were respectively $75 \%$ (very low risk), $51 \%$ (low risk), $40 \%$ (intermediate risk), 26\% (high risk) and 6\% (very high risk). This model is applicable to patients receiving either standard- or high-dose chemotherapy at the time of first recurrence, whereas the Beyer model is applicable to patients in second or late relapses. In conclusion, the use 
of prognostic models should allow for prospective identification of poor-prognosis patients who might benefit from the intensive chemotherapy approaches.

\section{Perspectives for the treatment of GCT relapsed/refractory patients}

For refractory patients, or those who have become refractory to cisplatin, salvage treatment strategies clearly must be explored. Taking the prognostic factors mentioned above into account, we know that HDCT is more effective in GCT patients with sensitive disease and low tumor burden, but no information is available on other predictive factors, such as biomolecular characteristics. In that context, it is well known that angiogenesis, as reflected by serum concentrations of vascular endothelial growth factor (VEGF) and other growth factors such as platelet-derived growth factor (PDGF), plays a functional role in the growth and progression of testicular GCTs (66).

Moreover, it has been shown that the expression of VEGF in patients with testicular GCTs is an indicator of metastatic disease. In an interesting work carried out in 1999, Fukuda et al. (67) reported that VEGF protein was expressed more highly in GCTs than in nonneoplastic tissues. VEGF expression in GCTs was correlated significantly with microvessel count, and both VEGF expression and microvessel count were correlated with metastatic disease. Thus, VEGF overexpression in GCT patients could represent an independent risk factor, particularly for those with nonseminomatous GCTs. For example, teratomas, the least chemosensitive of the nonseminomatous GCTs, appear to have the highest rates of VEGF expression compared to both seminomas and normal tissues (68).

Targeted therapies should be considered for such patients. Targeting VEGF with the monoclonal humanized antibody bevacizumab might be a promising treatment approach for patients with highly vascularized tumors such as GCTs. The combination of bevacizumab plus HDCT followed by autologous stem cell transplantation induced an unexpected dramatic response in a patient with highly chemotherapy refractory germ cell cancer (69).

Similarly, a recent phase II study by Nieto et al. (70) evaluating tandem HDCT combining BEV/GDMC (bevacizumab/gemcitabine, docetaxel, melphalan, and carboplatin) followed by BEV/ICE (bevacizumab/ifosfamide, carboplatin and etoposide) showed promising event-free survival $(63 \%, 95 \% \mathrm{Cl}: 49-81 \%)$ in patients with heavily pretreated and refractory GCT, exceeding the results expected with carboplatin/etoposide without bevacizumab.

\section{High-dose chemotherapy to treat breast and ovarian cancer}

High-dose chemotherapy in breast cancer was developed for use in an adjuvant setting or for metastatic disease. In those settings, several phase II studies were undertaken in the 1980s and the early 1990s to test the efficacy of HDCT with the addition of hematopoietic stem cell transplantation (71). The small number of patients included in each study limited further extrapolation of those studies. Moreover, an episode of scientific misconduct, which reported a considerable global survival benefit in the group of patients receiving high-dose therapy, was an essential contributor to the significant decrease or complete abandoning of this approach in most specialized centers (72).

More recently, two meta-analyses reviewed clinical trials using HDCT as adjuvant therapy or in the setting of metastatic disease. Berry et al. (73) analyzed 15 randomized clinical trials conducted between 1990 and 2002 that included 6210 patients, 3118 of whom received HDCT and 3092 received standard-dose chemotherapy. The principal objective was to determine whether patients with high-risk breast cancer could benefit from high-dose adjuvant chemotherapy. In 11 of 15 studies, the relapse risk was reduced in the HDCT group, and 3 of the 11 studies found a statistically significant reduction favoring HDCT. Regarding global survival, the difference between the study arms was not statistically significant, with the exception of the human epidermal growth factor receptor (HER)2-negative subgroup. In those patients, there was a $21 \%$ reduction in mortality risk, which was even more notable (33\%) in triple-negative (ER-, PR- and HER2negative) patients.

In a similar meta-analysis, Berry et al. (74) reviewed 6 randomized studies comparing HDCT and stem cell transplantation with conventional chemotherapy without stem cell transplantation in the setting of metastatic disease. The analysis included the results of studies from the BBCRG (Berlin Breast Cancer Research Group), the ECOG (Eastern Cooperative Oncology Group), the IBDIS (International Randomized Breast Cancer Dose Intensity Study), the NCIC (National Cancer Institute of Canada) and PEGASE 03/04, and revealed a statistically significant advantage of HDCT for PFS (median, 0.91 versus 0.69 years). However, this improvement in PFS was not associated with improved OS. Subgroup analysis suggested a benefit of HDCT for patients younger than 50 years of age, premenopausal patients, patients with softtissue metastases and patients presenting with two or more metastatic sites. However, covariable associations were weak and showed only a modest difference in global survival, and the authors were unable to conclude an overall benefit of HDCT.

Regarding metastatic disease, the French PEGASE 04 program (Programme d'Etudes des Greffes Autologues dans les Cancers de Sein or Autologous Transplants in Breast Cancer Studies Program) compared HDCT with standard chemotherapy protocols based on anthracyclines in patients with metastatic breast cancer and found that HDCT was able to slow disease 
progression without major toxicities. Furthermore, a trend towards improvement in global survival was demonstrated (75). In conclusion, the majority of randomized studies conducted in patients with high-risk disease as well as those with metastatic breast cancer reported an advantage in PFS (76).

High-dose chemotherapy regimens for the treatment of ovarian cancer emerged late compared with the development and study of similar treatments for breast cancer. For ovarian cancer, two principal strategies were developed: the use of HDCT for consolidation after attaining a complete or partial response; or as rescue therapy in the case of relapse or refractory disease.

Initial reports on the use of HDCT and stem cell transplantation (isolated from the marrow or peripheral blood) involved patients presenting with either resistant or refractory disease. Results from early studies demonstrated a favorable global response rate. However, the duration of the observed response remained limited. At the end of the 1990s, Stiff et al. (77) conducted a study in over 100 patients who presented with recurrent disease who had been treated with various HDCT protocols. Seventy patients received a combination of carboplatin, mitoxantrone and cyclophosphamide, 25 received melphalan and mitoxantrone and five received other combinations. The observed median overall survival in that study was 9.6 months for patients presenting with resistant disease and 23.1 months for patients presenting with disease sensitive to platinum-based therapies. This study strongly contributed to the identification of two predictive factors linked to the use of this approach. Thus, until today, chemosensitivity to platinum salts and minimal tumor burden before transplantation were the two most important factors to be considered when selecting a patient population that could benefit from high-dose therapy.

For patients with disease resistant to platinum salts, compounds with alternative mechanisms of action that do not demonstrate cross-resistance were evaluated. In France, high-dose topotecan, which primarily carries hematopoietic toxicity, was evaluated in a phase I protocol combined with hematopoietic stem cell support and administration of the hematopoietic growth factor G-CSF (78). Patients received an initial mobilization cycle $\left[5 \mu \mathrm{g} \cdot \mathrm{kg}^{-1} \cdot\right.$ day $^{-1}$ cyclophosphamide $3 \mathrm{mg} / \mathrm{m}^{2}+\mathrm{G}-\mathrm{CSF}$ (filgrastim)] followed by topotecan monotherapy. The maximum tolerated dose of topotecan was established at $9 \mathrm{mg} \cdot\left(\mathrm{m}^{2}\right)^{-1} \cdot$ day $^{-1}$ over 5 days $(45 \mathrm{mg} /$ $\mathrm{m}^{2}$ ). Following this study, increased doses of topotecan $\left(8-10 \mathrm{mg} \cdot\left(\mathrm{m}^{2}\right)^{-1} \cdot\right.$ day $\left.^{-1}\right)$ were combined with cyclophosphamide $\left(60 \mathrm{mg} \cdot \mathrm{kg}^{-1} \cdot\right.$ day $^{-1}$ over 2 days) in patients refractory or resistant to combination therapy with taxanes and platinumbased treatments. The maximum tolerated dose of topotecan associated with cyclophosphamide was similar to that for topotecan monotherapy, $9 \mathrm{mg} \cdot\left(\mathrm{m}^{2}\right)^{-1} \cdot$ day $^{-1}$ over 5 days (79).

More recently, a retrospective study (80) evaluated interest in the use of HDCT as consolidation therapy after surgery and taxane- and platinum-based therapy. In that study, 103 patients with advanced ovarian carcinoma were treated with conventional chemotherapy while 60 patients received HDCT with hematopoietic stem cell support. There was no advantage in global survival between the two groups. However, HDCT was associated with improved outcomes in younger patients ( $\leq 50$ years), with a median global survival of 54.6 versus 36 months for patients receiving conventional chemotherapy. Unfortunately, the promising results of these studies were not confirmed by phase III randomized studies $(81,82)$.

\section{Treatment-associated toxic side effects}

All HDCT regimens are associated with significant acute and chronic toxicities. Secondary effects related to high-dose therapies are directly related to the medication and therapeutic protocol used. The mortality rate associated with HDCT, initially near $20 \%$ (83), has notably decreased to $2-3 \%$ in most regimens that include stem cell transplantation. This progress is primarily linked to the introduction of peripherally harvested autologous hematopoietic stem cell transplantation, a broad choice of chemotherapeutic agents, and the use of hematopoietic growth factors.

The principal causes of hematologic toxicity are severe neutropenia, thrombocytopenia, and anemia. Acute nonhematologic toxicities include nausea, vomiting, diarrhea, fatigue, and mucositis.

The risk of hematologic malignancy or secondary solid tumors associated with chemotherapy is well known. For example, anthracyclines are associated with the development of secondary leukemias. However, the development of secondary solid tumors is much less common (84).

Interestingly, the development of secondary tumors has also been associated with the presence of potentially malignant cellular clones in the autologous transplant. The reinfusion of malignant cells could drive relapse (84). Consistent with those observations, circulating tumor cells detected in the peripheral blood could participate in the dissemination of advanced-stage solid tumors as metastases (85). However, the reinfusion of a contaminated stem cell transplant cannot alone explain recurrent disease following transplantation.

\section{Conclusion}

All HDCT regimens are associated with acute and latepresenting toxicities. With the development of stem cell transplantation and harvesting from peripheral blood rather than bone marrow, intensive therapy could be more easily tolerated. Multiple HDCT protocols were subsequently developed to treat solid tumors. Currently, GCTs are the only solid tumors for which HDCT is a therapeutic option.

HDCT is offered as a second-line therapy for GCT patients predicted to have a poor outcome with conventional-dose 
chemotherapy. This includes patients who present an extragonadal mediastinal primary site, one of the major predictors of adverse outcomes. Although most of those patients are usually treated in an identical fashion to patients with recurrent testicular cancer, some institutions offer them HDCT in the first-salvage setting. The use of first-salvage intensification in those patients appears reasonable, because most patients with a mediastinal primary site fail to obtain a durable CR following first-line therapy.

HDCT is also used for GCT patients who are not cured after salvage therapy using conventional doses of chemotherapy. Indeed, after two or more treatment regimens, HDCT is generally the only curative option. It is important to note that the administration of intensive therapy, which carries significant side effects, is reserved to specialized referral centers to assure optimum patient care outcomes.

Aside from GCTs, several other indications for HDCT have been tested. In breast cancer, this approach has been entirely abandoned at the majority of centers following an episode of scientific misconduct. Furthermore, the majority of high-dose therapy studies demonstrated improvement in PFS, but global survival remained unchanged. However, the current use of HDCT in the treatment of breast cancer has declined significantly. In addition, with the development of targeted therapies and novel treatment modalities for breast cancer, the publication of randomized studies reporting a benefit of HDCT in global survival passed essentially without notice in the medical community.

Similarly, in ovarian cancer, improved response rates were observed but responses were generally short and prolonged survival without relapse was rare. The lack of

\section{References}

1. Frei E III, Cucchi CA, Rosowsky A, Tantravahi R, Bernal S, Ervin TJ, et al. Alkylating agent resistance: in vitro studies with human cell lines. Proc Natl Acad Sci U S A 1985; 82: 2158-2162, doi: 10.1073/pnas.82.7.2158.

2. Devita VT, Schein PS. The use of drugs in combination for the treatment of cancer: rationale and results. N Engl J Med 1973; 288: 998-1006, doi: 10.1056/NEJM19730510288 1905.

3. Motabi IH, DiPersio JF. Advances in stem cell mobilization. Blood Rev 2012; 26: 267-278, doi: 10.1016/j.blre.2012.09. 003.

4. Duong HK, Savani BN, Copelan E, Devine S, Costa LJ, Wingard JR, et al. Peripheral blood progenitor cell mobilization for autologous and allogeneic hematopoietic cell transplantation: guidelines from the American Society for Blood and Marrow Transplantation. Biol Blood Marrow Transplant 2014; 20: 1262-1273, doi: 10.1016/j.bbmt.2014. 05.003.

5. Huyghe E, Plante P, Thonneau PF. Testicular cancer variations in time and space in Europe. Eur Urol 2007; 51: 621-628, doi: 10.1016/j.eururo.2006.08.024. improvement in global survival led to the conclusion that there was no role for intensive therapy in those cancers outside clinical trials.

It is important to mention that certain authors suggest that a definitive end of HDCT for breast or ovarian cancer might be premature if one considers three major points: i) The prognosis of patients with high-risk tumors and metastatic disease has evolved little in the past 20 years, and in particular, targeted therapies have had a significant impact only on subgroups of breast cancer patients who overexpress HER2. ii) An improvement of PFS was observed in the majority of studies, and meta-analyses show that a benefit in PFS is sufficient for the approval of novel anticancer drugs in the setting of metastatic disease (77). iii) In high-risk breast cancer, two European studies demonstrated a benefit of HDCT in global survival in HER2-negative (86) and triple-negative patients (87).

In the future, these results could evolve if new medications become available for HDCT regimens. Agents such as bevacizumab or trastuzumab as well as immunotherapy could play a decisive role in the development of novel therapeutic trials involving HDCT. Similarly, the management of GCT patients may be improved with the identification of informative biomarkers. For example, the determination of the BRCA genetic profile could be used to select patients most likely to benefit from intensive chemotherapy, notably those with platinum-resistant ovarian cancer.

\section{Supplementary Material}

Click here to view [pdf]
6. Reuter VE. Origins and molecular biology of testicular germ cell tumors. Mod Pathol 2005; 18 (Suppl 2): S51-S60, doi: 10.1038/modpathol.3800309.

7. Classen J, Souchon R, Hehr T, Bamberg M. Treatment of early stage testicular seminoma. J Cancer Res Clin Oncol 2001; 127: 475-481, doi: 10.1007/s004320100243.

8. Shelley MD, Burgon K, Mason MD. Treatment of testicular germ-cell cancer: a cochrane evidence-based systematic review. Cancer Treat Rev 2002; 28: 237-253, doi: 10.1016/ S0305-7372(02)00059-2.

9. Bosl GJ, Motzer RJ. Testicular germ-cell cancer. N Engl J Med 1997; 337: 242-253, doi: 10.1056/NEJM1997072433 70406.

10. Atkin NB, Baker MC. i(12p): specific chromosomal marker in seminoma and malignant teratoma of the testis? Cancer Genet Cytogenet 1983; 10: 199-204, doi: 10.1016/01654608(83)90125-5.

11. Sandberg AA, Meloni AM, Suijkerbuijk RF. Reviews of chromosome studies in urological tumors. III. Cytogenetics and genes in testicular tumors. J Urol 1996; 155: 15311556, doi: 10.1016/S0022-5347(01)66124-X. 
12. Looijenga LH, Zafarana G, Grygalewicz B, Summersgill B, Debiec-Rychter M, Veltman J, et al. Role of gain of $12 p$ in germ cell tumour development. APMIS 2003; 111: 161-171, doi: 10.1034/j.1600-0463.2003.11101201.x.

13. Korkola JE, Houldsworth J, Chadalavada RS, Olshen AB, Dobrzynski D, Reuter VE, et al. Down-regulation of stem cell genes, including those in a 200-kb gene cluster at 12p13.31, is associated with in vivo differentiation of human male germ cell tumors. Cancer Res 2006; 66: 820-827, doi: 10.1158/ 0008-5472.CAN-05-2445.

14. Mostert MC, Verkerk AJ, van de Pol M, Heighway J, Marynen $\mathrm{P}$, Rosenberg $\mathrm{C}$, et al. Identification of the critical region of $12 p$ over-representation in testicular germ cell tumors of adolescents and adults. Oncogene 1998; 16: 2617-2627, doi: 10.1038/sj.onc.1201787.

15. Goddard NC, McIntyre A, Summersgill B, Gilbert D, Kitazawa S, Shipley J. KIT and RAS signalling pathways in testicular germ cell tumours: new data and a review of the literature. Int J Androl 2007; 30: 337-348, doi: 10.1111/ j.1365-2605.2007.00769.x.

16. Einhorn LH, Donohue J. Cis-diamminedichloroplatinum, vinblastine, and bleomycin combination chemotherapy in disseminated testicular cancer. Ann Intern Med 1977; 87: 293-298, doi: 10.7326/0003-4819-87-3-293.

17. Feldman DR, Bosl GJ, Sheinfeld J, Motzer RJ. Medical treatment of advanced testicular cancer. JAMA 2008; 299: 672-684, doi: 10.1001/jama.299.6.672.

18. Masters JR, Osborne EJ, Walker MC, Parris CN. Hypersensitivity of human testis-tumour cell lines to chemotherapeutic drugs. Int J Cancer 1993; 53: 340-346, doi: 10.1002/ijc.2910530228.

19. Huddart RA, Titley J, Robertson D, Williams GT, Horwich A, Cooper CS. Programmed cell death in response to chemotherapeutic agents in human germ cell tumour lines. Eur J Cancer 1995; 31A: 739-746, doi: 10.1016/09598049(95)00047-M.

20. Peng $H Q$, Hogg D, Malkin D, Bailey D, Gallie BL, Bulbul M, et al. Mutations of the p53 gene do not occur in testis cancer. Cancer Res 1993; 53: 3574-3578.

21. Lutzker SG. P53 tumour suppressor gene and germ cell neoplasia. APMIS 1998; 106: 85-89, doi: 10.1111/j.16990463.1998.tb01323.x.

22. Lutzker SG, Mathew R, Taller DR. A p53 dose-response relationship for sensitivity to DNA damage in isogenic teratocarcinoma cells. Oncogene 2001; 20: 2982-2986, doi: $10.1038 /$ sj.onc.1204394.

23. Kerley-Hamilton JS, Pike AM, Li N, DiRenzo J, Spinella MJ. A p53-dominant transcriptional response to cisplatin in testicular germ cell tumor-derived human embryonal carcinoma. Oncogene 2005; 24: 6090-6100, doi: 10.1038/ sj.onc. 1208755 .

24. Gutekunst $M$, Oren $M$, Weilbacher $A$, Dengler $M A$, Markwardt C, Thomale J, et al. p53 hypersensitivity is the predominant mechanism of the unique responsiveness of testicular germ cell tumor (TGCT) cells to cisplatin. PLoS One 2011; 6: e19198, doi: 10.1371/journal.pone.0019198.

25. Bartkova J, Rajpert-De Meyts E, Skakkebaek NE, Lukas J, Bartek J. Deregulation of the G1/S-phase control in human testicular germ cell tumours. APMIS 2003; 111: 252-265, doi: 10.1034/j.1600-0463.2003.1110129.x.

26. Welsh C, Day R, McGurk C, Masters JR, Wood RD, Koberle
B. Reduced levels of XPA, ERCC1 and XPF DNA repair proteins in testis tumor cell lines. Int $J$ Cancer 2004; 110: 352-361, doi: 10.1002/ijc.20134.

27. Eastman A. Reevaluation of interaction of cisdichloro(ethylenediamine)platinum(II) with DNA. Biochemistry 1986; 25: 3912-3915, doi: 10.1021/bi00361a026.

28. McHugh PJ, Spanswick VJ, Hartley JA. Repair of DNA interstrand crosslinks: molecular mechanisms and clinical relevance. Lancet Oncol 2001; 2: 483-490, doi: 10.1016/ S1470-2045(01)00454-5.

29. Koberle B, Roginskaya V, Zima KS, Masters JR, Wood RD. Elevation of XPA protein level in testis tumor cells without increasing resistance to cisplatin or UV radiation. Mol Carcinog 2008; 47: 580-586, doi: 10.1002/mc.20418.

30. Usanova S, Piee-Staffa A, Sied U, Thomale J, Schneider A, Kaina B, et al. Cisplatin sensitivity of testis tumour cells is due to deficiency in interstrand-crosslink repair and low ERCC1-XPF expression. Mol Cancer 2010; 9: 248, doi: 10.1186/1476-4598-9-248.

31. Ferry KV, Hamilton TC, Johnson SW. Increased nucleotide excision repair in cisplatin-resistant ovarian cancer cells: role of ERCC1-XPF. Biochem Pharmacol 2000; 60: 13051313, doi: 10.1016/S0006-2952(00)00441-X.

32. Koberle B, Tomicic MT, Usanova S, Kaina B. Cisplatin resistance: preclinical findings and clinical implications. Biochim Biophys Acta 2010; 1806: 172-182.

33. Cavallo F, Feldman DR, Barchi M. Revisiting DNA damage repair, p53-mediated apoptosis and cisplatin sensitivity in germ cell tumors. Int J Dev Biol 2013; 57: 273-280, doi: 10.1387/ijdb.130135mb.

34. Andrews PW. Retinoic acid induces neuronal differentiation of a cloned human embryonal carcinoma cell line in vitro. Dev Biol 1984; 103: 285-293, doi: 10.1016/00121606(84)90316-6.

35. Timmer-Bosscha H, de Vries EG, Meijer C, Oosterhuis JW, Mulder NH. Differential effects of all-trans-retinoic acid, docosahexaenoic acid, and hexadecylphosphocholine on cisplatin-induced cytotoxicity and apoptosis in a cisplantinsensitive and resistant human embryonal carcinoma cell line. Cancer Chemother Pharmacol 1998; 41: 469-476, doi: 10.1007/s002800050769.

36. Cavallo F, Graziani G, Antinozzi C, Feldman DR, Houldsworth J, Bosl GJ, et al. Reduced proficiency in homologous recombination underlies the high sensitivity of embryonal carcinoma testicular germ cell tumors to Cisplatin and poly (adp-ribose) polymerase inhibition PLoS One 2012; 7: e51563, doi: 10.1371/journal.pone. 0051563

37. Koster R, Timmer-Bosscha H, Bischoff R, Gietema JA, de Jong $S$. Disruption of the MDM2-p53 interaction strongly potentiates p53-dependent apoptosis in cisplatin-resistant human testicular carcinoma cells via the Fas/FasL pathway. Cell Death Dis 2011; 2: e148, doi: 10.1038/cddis.2011.33.

38. International Germ Cell Cancer Collaborative Group. International Germ Cell Consensus Classification: a prognostic factor-based staging system for metastatic germ cell cancers. J Clin Oncol 1997; 15: 594-603.

39. Einhorn LH. Treatment of testicular cancer: a new and improved model. J Clin Oncol 1990; 8: 1777-1781.

40. Schmoll HJ, Souchon R, Krege S, Albers P, Beyer J, Kollmannsberger $\mathrm{C}$, et al. European consensus on 
diagnosis and treatment of germ cell cancer: a report of the European Germ Cell Cancer Consensus Group (EGCCCG). Ann Oncol 2004; 15: 1377-1399, doi: 10.1093/annonc/ mdh301.

41. Mead GM, Cullen MH, Huddart R, Harper P, Rustin GJ, Cook PA, et al. A phase II trial of TIP (paclitaxel, ifosfamide and cisplatin) given as second-line (post-BEP) salvage chemotherapy for patients with metastatic germ cell cancer: a medical research council trial. Br J Cancer 2005; 93: 178184, doi: 10.1038/sj.bjc.6602682.

42. Kondagunta GV, Bacik J, Donadio A, Bajorin D, Marion S, Sheinfeld J, et al. Combination of paclitaxel, ifosfamide, and cisplatin is an effective second-line therapy for patients with relapsed testicular germ cell tumors. J Clin Oncol 2005; 23: 6549-6555, doi: 10.1200/JCO.2005.19.638.

43. McCaffrey JA, Mazumdar M, Bajorin DF, Bosl GJ, Vlamis V, Motzer RJ. Ifosfamide- and cisplatin-containing chemotherapy as first-line salvage therapy in germ cell tumors: response and survival. J Clin Oncol 1997; 15: 2559-2563.

44. Motzer RJ, Mazumdar M, Gulati SC, Bajorin DF, Lyn P, Vlamis $\mathrm{V}$, et al. Phase II trial of high-dose carboplatin and etoposide with autologous bone marrow transplantation in first-line therapy for patients with poor-risk germ cell tumors. J Natl Cancer Inst 1993; 85: 1828-1835, doi: 10.1093/jnci/ 85.22.1828.

45. Motzer RJ, Mazumdar M, Bajorin DF, Bosl GJ, Lyn P, Vlamis V. High-dose carboplatin, etoposide, and cyclophosphamide with autologous bone marrow transplantation in first-line therapy for patients with poor-risk germ cell tumors. J Clin Oncol 1997; 15: 2546-2552.

46. Bokemeyer $C$, Kollmannsberger $C$, Meisner $C$, Harstrick A, Beyer J, Metzner B, et al. First-line high-dose chemotherapy compared with standard-dose PEB/VIP chemotherapy in patients with advanced germ cell tumors: A multivariate and matched-pair analysis. J Clin Oncol 1999; 17: 3450-3456.

47. Schmoll HJ, Kollmannsberger C, Metzner B, Hartmann JT, Schleucher N, Schoffski P, et al. Long-term results of firstline sequential high-dose etoposide, ifosfamide, and cisplatin chemotherapy plus autologous stem cell support for patients with advanced metastatic germ cell cancer: an extended phase I/II study of the German Testicular Cancer Study Group. J Clin Oncol 2003; 21: 4083-4091, doi: 10.1200/JCO.2003.09.035.

48. Bokemeyer C, Schleucher N, Metzner B, Thomas M, Rick $\mathrm{O}$, Schmoll $\mathrm{HJ}$, et al. First-line sequential high-dose VIP chemotherapy with autologous transplantation for patients with primary mediastinal nonseminomatous germ cell tumours: a prospective trial. Br J Cancer 2003; 89: 29-35, doi: $10.1038 /$ sj.bjc.6600999.

49. Hartmann JT, Gauler T, Metzner B, Gerl A, Casper J, Rick $O$, et al. Phase $1 / I I$ study of sequential dose-intensified ifosfamide, cisplatin, and etoposide plus paclitaxel as induction chemotherapy for poor prognosis germ cell tumors by the German Testicular Cancer Study Group. J Clin Oncol 2007; 25: 5742-5747, doi: 10.1200/JCO.2007.11.9099.

50. Droz JP, Kramar A, Biron P, Pico JL, Kerbrat P, Peny J, et al. Failure of high-dose cyclophosphamide and etoposide combined with double-dose cisplatin and bone marrow support in patients with high-volume metastatic nonseminomatous germ-cell tumours: mature results of a randomised trial. Eur Urol 2007; 51: 739-746, doi: 10.1016/ j.eururo.2006.10.035

51. Motzer RJ, Nichols CJ, Margolin KA, Bacik J, Richardson PG, Vogelzang $\mathrm{NJ}$, et al. Phase III randomized trial of conventional-dose chemotherapy with or without high-dose chemotherapy and autologous hematopoietic stem-cell rescue as first-line treatment for patients with poorprognosis metastatic germ cell tumors. $J$ Clin Oncol 2007; 25: 247-256, doi: 10.1200/JCO.2005.05.4528.

52. Daugaard G, Skoneczna I, Aass N, de Wit R, De Santis M, Dumez $\mathrm{H}$, et al. A randomized phase III study comparing standard dose BEP with sequential high-dose cisplatin, etoposide, and ifosfamide (VIP) plus stem-cell support in males with poor-prognosis germ-cell cancer. An intergroup study of EORTC, GTCSG, and Grupo Germinal (EORTC 30974). Ann Oncol 2011; 22: 1054-1061, doi: 10.1093/ annonc/mdq575

53. Lorch A, Bascoul-Mollevi C, Kramar A, Einhorn L, Necchi A, Massard $\mathrm{C}$, et al. Conventional-dose versus high-dose chemotherapy as first salvage treatment in male patients with metastatic germ cell tumors: evidence from a large international database. J Clin Oncol 2011; 29: 2178-2184, doi: $10.1200 / J C O .2010 .32 .6678$

54. Lorch A, Beyer J, Bascoul-Mollevi C, Kramar A, Einhorn LH, Necchi $A$, et al. Prognostic factors in patients with metastatic germ cell tumors who experienced treatment failure with cisplatin-based first-line chemotherapy. J Clin Oncol 2010; 28: 4906-4911, doi: 10.1200/JCO.2009.26. 8128.

55. Lorch A, Kleinhans A, Kramar A, Kollmannsberger CK, Hartmann JT, Bokemeyer C, et al. Sequential versus single high-dose chemotherapy in patients with relapsed or refractory germ cell tumors: long-term results of a prospective randomized trial. J Clin Oncol 2012; 30: 800-805, doi: 10.1200/JCO.2011.38.6391.

56. Feldman DR, Sheinfeld J, Bajorin DF, Fischer P, Turkula S, Ishill $\mathrm{N}$, et al. TI-CE high-dose chemotherapy for patients with previously treated germ cell tumors: results and prognostic factor analysis. J Clin Oncol 2010; 28: 17061713, doi: 10.1200/JCO.2009.25.1561.

57. Beyer J, Albers P, Altena R, Aparicio J, Bokemeyer C, Busch $\mathrm{J}$, et al. Maintaining success, reducing treatment burden, focusing on survivorship: highlights from the third European consensus conference on diagnosis and treatment of germ-cell cancer. Ann Oncol 2013; 24: 878-888, doi: 10.1093/annonc/mds579.

58. Einhorn LH, Williams SD, Chamness A, Brames MJ, Perkins SM, Abonour R. High-dose chemotherapy and stem-cell rescue for metastatic germ-cell tumors. $N$ Engl $J$ Med 2007; 357: 340-348, doi: 10.1056/NEJMoa067749.

59. Pico JL, Rosti G, Kramar A, Wandt H, Koza V, Salvioni R, et al. A randomised trial of high-dose chemotherapy in the salvage treatment of patients failing first-line platinum chemotherapy for advanced germ cell tumours. Ann Oncol 2005; 16: 1152-1159, doi: 10.1093/annonc/mdi228.

60. Feldman DR, Huddart R, Hall E, Beyer J, Powles T. Is high dose therapy superior to conventional dose therapy as initial treatment for relapsed germ cell tumors? The TIGER Trial. J Cancer 2011; 2: 374-377, doi: 10.7150/jca.2.374.

61. Nichols CR, Tricot G, Williams SD, van Besien K, Loehrer $\mathrm{PJ}$, Roth BJ, et al. Dose-intensive chemotherapy in refractory germ cell cancer - a phase $\mathrm{I} / \mathrm{II}$ trial of high-dose 
carboplatin and etoposide with autologous bone marrow transplantation. J Clin Oncol 1989; 7: 932-939.

62. Siegert W, Beyer J, Strohscheer I, Baurmann H, Oettle H, Zingsem J, et al. High-dose treatment with carboplatin, etoposide, and ifosfamide followed by autologous stem-cell transplantation in relapsed or refractory germ cell cancer: a phase I/II study. The German Testicular Cancer Cooperative Study Group. J Clin Oncol 1994; 12: 12231231.

63. Lotz JP, Bui B, Gomez F, Theodore C, Caty A, Fizazi K, et al. Sequential high-dose chemotherapy protocol for relapsed poor prognosis germ cell tumors combining two mobilization and cytoreductive treatments followed by three high-dose chemotherapy regimens supported by autologous stem cell transplantation. Results of the phase II multicentric TAXIF trial. Ann Oncol 2005; 16: 411-418, doi: 10.1093/annonc/mdi087.

64. Selle F, Wittnebel S, Biron P, Gravis G, Roubaud G, Bui BN, et al. A phase II trial of high-dose chemotherapy (HDCT) supported by hematopoietic stem-cell transplantation (HSCT) in germ-cell tumors (GCTs) patients failing cisplatin-based chemotherapy: the Multicentric TAXIF II study. Ann Oncol 2014; 25: 1775-1782, doi: 10.1093/annonc/ mdu198.

65. Beyer J, Kramar A, Mandanas R, Linkesch W, Greinix A, Droz JP, et al. High-dose chemotherapy as salvage treatment in germ cell tumors: a multivariate analysis of prognostic variables. J Clin Oncol 1996; 14: 2638-2645.

66. Bentas W, Beecken WD, Glienke W, Binder J, Schuldes H. Serum levels of basic fibroblast growth factor reflect disseminated disease in patients with testicular germ cell tumors. Urol Res 2003; 30: 390-393.

67. Fukuda S, Shirahama T, Imazono Y, Tsushima T, Ohmori $H$, Kayajima $T$, et al. Expression of vascular endothelial growth factor in patients with testicular germ cell tumors as an indicator of metastatic disease. Cancer 1999; 85: 13231330, doi: 10.1002/(SICl)1097-0142(19990315)85:6<13 23::AID-CNCR15>3.0.CO;2-G

68. Jones A, Fujiyama C, Turner K, Fuggle S, Cranston D, Turley $\mathrm{H}$, et al. Angiogenesis and lymphangiogenesis in stage 1 germ cell tumours of the testis. BJU Int 2000; 86: 80-86, doi: 10.1046/j.1464-410x.2000.00660.x.

69. Voigt W, Kegel T, Maher G, Jordan K, Muller L, Schmoll HJ. Bevacizumab plus high-dose ifosfamide, etoposide and carboplatin (HD-ICE) as third-line salvage chemotherapy induced an unexpected dramatic response in highly platinum refractory germ-cell cancer. Ann Oncol 2006; 17: 531-533, doi: 10.1093/annonc/mdj028.

70. Nieto $\mathrm{Y}, \mathrm{Tu} \mathrm{S}-\mathrm{M}$, Jones RB, Tannir NM, Bassett RL, Margolin KA, et al. Phase 2 trial of bevacizumab (BEV)/highdose chemotherapy (HDC) with autologous stem-cell transplant (ASCT) for refractory germ-cell tumors (GCT). ASCO Annual Meeting. J Clin Oncol 2014; 32 (Suppl; abstract 4517): $5 \mathrm{~s}$.

71. Peters WP, Ross M, Vredenburgh JJ, Meisenberg B, Marks LB, Winer E, et al. High-dose chemotherapy and autologous bone marrow support as consolidation after standard-dose adjuvant therapy for high-risk primary breast cancer. J Clin Oncol 1993; 11: 1132-1143.

72. Weiss RB, Rifkin RM, Stewart FM, Theriault RL, Williams LA, Herman AA, et al. High-dose chemotherapy for high-risk primary breast cancer: an on-site review of the Bezwoda study. Lancet 2000; 355: 999-1003, doi: 10.1016/S01406736(00)90024-2.

73. Berry DA, Ueno NT, Johnson MM, Lei X, Caputo J, Rodenhuis $\mathrm{S}$, et al. High-dose chemotherapy with autologous stem-cell support as adjuvant therapy in breast cancer: overview of 15 randomized trials. $J$ Clin Oncol 2011; 29: 3214-3223, doi: 10.1200/JCO.2010.32.5910.

74. Berry DA, Ueno NT, Johnson MM, Lei X, Caputo J, Smith $D A$, et al. High-dose chemotherapy with autologous hematopoietic stem-cell transplantation in metastatic breast cancer: overview of six randomized trials. J Clin Oncol 2011; 29: 3224-3231, doi: 10.1200/JCO.2010.32.5936.

75. Lotz JP, Cure H, Janvier M, Asselain B, Morvan F, Legros $\mathrm{M}$, et al. High-dose chemotherapy with haematopoietic stem cell transplantation for metastatic breast cancer patients: final results of the French multicentric randomised $\mathrm{CMA}$ / PEGASE 04 protocol. Eur J Cancer 2005; 41: 71-80, doi: 10.1016/j.ejca.2004.09.006.

76. Martino M, Bottini A, Rosti G, Generali D, Secondino S, Barni S, et al. Critical issues on high-dose chemotherapy with autologous hematopoietic progenitor cell transplantation in breast cancer patients. Expert Opin Biol Ther 2012; 12: 1505-1515, doi: 10.1517/14712598.2012.721767.

77. Stiff PJ, Bayer R, Kerger C, Potkul RK, Malhotra D, Peace DJ, et al. High-dose chemotherapy with autologous transplantation for persistent/relapsed ovarian cancer: a multivariate analysis of survival for 100 consecutively treated patients. J Clin Oncol 1997; 15: 1309-1317.

78. Lotz JP, Pautier P, Selle F, Viens P, Fabbro M, Lokiec F, et al. Phase I study of high-dose topotecan with haematopoietic stem cell support in the treatment of ovarian carcinomas: the ITOV 01 protocol. Bone Marrow Transplant 2006; 37: 669-675, doi: 10.1038/sj.bmt. 1705310.

79. Lotz JP, Pautier P, Selle F, Fabbro M, Viens P, Ribrag V, et al. A phase I study combining high-dose (HD) topotecan (TPC) plus cyclophosphamide (CPM) with blood stem cells support in poor prognosis ovarian carcinoma (OC): The ITOV 01bis protocol.ASCO Annual Meeting Proceedings. J Clin Oncol 2007; 25 (Suppl): 16061.

80. Sabatier R, Goncalves A, Bertucci F, Capiello MA, Rousseau F, Lambaudie E, et al. Are there candidates for high-dose chemotherapy in ovarian carcinoma? J Exp Clin Cancer Res 2012; 31: 87, doi: 10.1186/1756-9966-31-87.

81. Mobus V, Wandt H, Frickhofen N, Bengala C, Champion K, Kimmig R, et al. Phase III trial of high-dose sequential chemotherapy with peripheral blood stem cell support compared with standard dose chemotherapy for first-line treatment of advanced ovarian cancer: intergroup trial of the AGO-Ovar/AIO and EBMT. J Clin Oncol 2007; 25: 41874193, doi: 10.1200/JCO.2006.09.7527.

82. Papadimitriou C, Dafni U, Anagnostopoulos A, Vlachos G, Voulgaris Z, Rodolakis A, et al. High-dose melphalan and autologous stem cell transplantation as consolidation treatment in patients with chemosensitive ovarian cancer: results of a single-institution randomized trial. Bone Marrow Transplant 2008; 41: 547-554, doi: 10.1038/sj.bmt.1705925.

83. Lazarus HM, Reed MD, Spitzer TR, Rabaa MS, Blumer JL. High-dose iv thiotepa and cryopreserved autologous bone marrow transplantation for therapy of refractory cancer. Cancer Treat Rep 1987; 71: 689-695. 
84. Kroger N, Zander AR, Martinelli G, Ferrante P, Moraleda $\mathrm{JM}$, Da Prada GA, et al. Low incidence of secondary myelodysplasia and acute myeloid leukemia after high-dose chemotherapy as adjuvant therapy for breast cancer patients: a study by the Solid Tumors Working Party of the European Group for Blood and Marrow Transplantation. Ann Oncol 2003; 14: 554-558, doi: 10.1093/annonc/ mdg161.

85. Shimoni A, Korbling M. Tumor cell contamination in reinfused stem cell autografts: does it have clinical significance? Crit Rev Oncol Hematol 2002; 41: 241-250, doi: 10.1016/S1040-8428(01)00160-3.

86. Rodenhuis S, Bontenbal M, van Hoesel QG, Smit WM, Nooij $M A$, Voest EE, et al. Efficacy of high-dose alkylating chemotherapy in HER2/neu-negative breast cancer. Ann Oncol 2006; 17: 588-596, doi: 10.1093/annonc/mdl001.

87. Gluz O, Nitz UA, Harbeck N, Ting E, Kates R, Herr A, et al. Triple-negative high-risk breast cancer derives particular benefit from dose intensification of adjuvant chemotherapy: results of WSG AM-01 trial. Ann Oncol 2008; 19: 861-870, doi: 10.1093/annonc/mdm551.

88. Rick O, Bokemeyer C, Beyer J, Hartmann JT, Schwella N, Kingreen D, et al. Salvage treatment with paclitaxel, ifosfamide, and cisplatin plus high-dose carboplatin, etoposide, and thiotepa followed by autologous stem-cell rescue in patients with relapsed or refractory germ cell cancer. J Clin Oncol 2001; 19: 81-88.

89. De Giorgi U, Demirer T, Wandt H, Taverna C, Siegert W, Bornhauser M, et al. Second-line high-dose chemotherapy in patients with mediastinal and retroperitoneal primary nonseminomatous germ cell tumors: the EBMT experience. Ann Oncol 2005; 16: 146-151, doi: 10.1093/annonc/ mdi017.

90. Lorch A, Neubauer A, Hackenthal M, Dieing A, Hartmann JT, Rick O, et al. High-dose chemotherapy (HDCT) as second-salvage treatment in patients with multiple relapsed or refractory germ-cell tumors. Ann Oncol 2010; 21: 820825, doi: 10.1093/annonc/mdp366. 